\title{
Association of Education and Knowledge of HIV with HIV Stigma in Thirteen Selected African Countries
}

\author{
Gerhard Fortwengel $^{1}{ }^{\text {* }}$, Sam Ibeneme ${ }^{2}$, Jacqueline Behnsen ${ }^{1}$, Lars Heinrich ${ }^{1}$, Stephanie Ilenseer ${ }^{1}$, \\ Susanna Kirchner ${ }^{1}$, Ya-Jui Liang ${ }^{1}$, Marie Lindemann', Jana-Elena Michaelis ${ }^{1}$, Melanie Müller ${ }^{1}$, \\ Kira Schütze $^{1}$, Christina Valtin ${ }^{1}$
}

${ }^{1}$ Department of Medical Information Management, University of Applied Sciences and Arts, Hannover, Germany

${ }^{2}$ Department of Medical Rehabilitation; University of Nigeria, Enugu, Nigeria

\section{Email address:}

gerhard.fortwengel@hs-hannover.de(G. Fortwengel)

*Corresponding author

\section{To cite this article:}

Gerhard Fortwengel, Sam Ibeneme, Jacqueline Behnsen, Lars Heinrich, Stephanie Ilenseer, Susanna Kirchner, Ya-Jui Liang, Marie Lindemann, Jana-Elena Michaelis, Melanie Müller, Kira Schütze, Christina Valtin. Association of Education and Knowledge of HIV with HIV Stigma in Thirteen Selected African Countries. Central African Journal of Public Health. Vol. 4, No. 2, 2018, pp. 48-58. doi: $10.11648 /$ j.cajph.20180402.13

Received: February 21, 2018; Accepted: March 21, 2018; Published: May 2, 2018

\begin{abstract}
Majority of African countries have high stigma index(HSI) and are mostly populated by rural dwellers with high levels of illiteracy/ignorance. Therefore, poor education and knowledge of human immune deficiency virus(HIV) infection might be key drivers of stigmatization. Eight countries with a stigma index(STI) $>40 \%$ (Niger, Guinea, Ghana, Sierra Leone, Liberia, Mali, Togo, and Democratic Republic of Congo) of 32 African countries with listed STI by UNAIDS, and three (Rwanda, Zambia, and Namibia), with a low stigma index (LSI) of 20\%, were descriptively analyzed. Four knowledge classes $(\leq 25 \%$-class one; $>25 \% \leq 50 \%$-class two; $>50 \% \leq 75 \%$ class three; $>75 \%$-class four), and categories of stigmatisation score $(<0.5$-class one; $0.5<1.0$-class two; $1.0<1.5$-class three and $>1.5$-class four - signifying little, medium, high and very high tendency to stigmatize, respectively), were created based on respondents 'answers to twelve questions assessing knowledge of HIV, and four questions assessing stigmatisation of HIV-positive people, respectively. Data were characterized and evaluated by frequency tables using IBM SPSS Software. Respondents in knowledge classes three and four, mainly comprised urban dwellers in both LSI (98.0\%urban vs $96.5 \%$ rural), and HSI (80.3\%urban vs $64.5 \%$ rural) countries. Females had higher educational attainment than males in countries with LSI (98.35\%females vs $97.6 \%$ males) than his (79.8\% females vs $81.6 \%$ males). However, males expressed positive views $(<0.5$-class one) about having an HIV-positive teacher, continuing to teach (i.e. least tendency for social stigmatization), and would buy vegetables from an HIV-positive vendor (i.e. least tendency for physical stigmatization), than females. Meanwhile, $48 \%$ of respondents would not buy vegetables from an infected vendor, yet they knew that HIV will not be transmitted by sharing food with an infected person. Impact factors of positive attitudes towards HIV are urbanization, educational attainment, and knowledge about HIV. LSI countries are distinguished from HSI countries by higher female educational attainment and knowledge about HIV than male, which may impact HIV stigmatization, and could be of socio-cultural significance. Lesser tendency to stigmatize among males than females may suggest that socio-cultural factors which enable stigmatization may be gender-related. The greater tendency towards physical than social stigmatization may reflect respondents' perception that physical contact enables HIV transmission. The contradiction between knowledge and belief was evident hence almost half of those who knew the mode of transmission of HIV, had a negative attitude towards an infected vendor.
\end{abstract}

Keywords: Level of Education, Knowledge of HIV Infection, HIV-Stigma, African Countries 


\section{Introduction}

The HIV prevalence is approximately $2.2 \%$ in Western and Central Africa, and $7.1 \%$ in Eastern and Southern Africa. [1, 2, 3] In most cases, the rural populace accounts for the greatest burden of the disease. [4]However, for unknown reasons stigma and discrimination in connection with this disease are a frequently occurring problem in Africa. $[3,5]$ It was considered that over $70 \%$ of the African population are rural dwellers, $[6,7]$ who live in cultural communities with a high level of poverty, illiteracy, ignorance, and diseases [3, 8-14] due to poor health care and educational facilities. Therefore, poor knowledge and education on HIV infection are likely to arise. Invariably, the stigma associated with HIV, and discrimination against people living with it may be borne out of ignorance/lack/poor education and knowledge of the disease.

In most cultural communities, incurable diseases have been perceived as a direct retribution from the "gods of the land" for acts of sacrilege/taboos [15] purportedly committed by the victims. This often leads to outright stigmatization and isolation of victims from all forms of social interactions [3] including visitations, communal associations, community participation and even outright excommunication from the community as a way of assuaging the gods to contain the scourge. In this context, stigmatization encompasses moral, physical, and social dimensions. The unwillingness of HIVnegative individuals to share meals, drinks or social space with HIV-positive individuals reflects the physical dimension of stigmatization. [16] Physical stigmatization may also derive from a moral persuasion and perception that HIVpositive individuals were sexually promiscuous, which is a behavior deemed morally reprehensible in African traditional societies. Therefore, moral stigmatization seems to provide the basis and cultural justification for other forms of stigmatization. The social stigma attached to such class of individuals as sex workers or lorry drivers, among whom HIV prevalence is high ${ }^{3}$ also seem to derive from moral stigma. Therefore, the fear of possible stigmatization may explain why the vulnerable population, often hesitate or refuse to uptake HIV screening test on time or disclose their status to their spouses/friends/family/sexual partners. [17] Therefore, removing stigmatization is a significant component of HIV/AIDS therapy and prevention. The discrimination and stigmatization of HIV-infected people can cause shame and fear, and so they may avoid consultation and treatments at early stages. For the success of prevention campaigns und HIV-treatment, it is important to understand the drivers of HIV stigma and discrimination, especially in countries with high HIV-prevalence. In this regard, it was considered that education and knowledge of HIV may play important roles in addressing HIV-related stigmatization.

Apparently, ignorance of the mode of transmission of HIV reinforces the belief that HIV is solely transmitted through unprotected sex. [18] The myth created by the incurable nature of HIV and its associated complications, all of which diminish the quality of life of the infected people, seem to instill a transcendental fear [17] that may be dispelled with sound education and knowledge of the disease. This study investigated the association of education and knowledge of HIV stigma in selected African countries. It was considered that education and knowledge about the transmission of HIV may improve perception and handling of individuals infected with HIV. This could be the basis for a tolerant and open society which aims at getting this epidemic disease under control. Stigmatization for the purpose of this study ma is a conception used to explain cultural relationship that rejects, discriminates or stereotypes those having characteristics, behaviors or physical appearance that is different from cultural norms. [18]

\section{Methods}

\subsection{Selection of Countries}

Out of all 54 African countries, 32 had a listed stigma index by UNAIDS. [2] Based on UNAIDS data (2015) on HIV stigma index, eight Sub-Saharan countries with an index above $40 \%$ and three with an index under $20 \%$ were analyzed. Countries where no data was available on UNAIDS and the DHS Program (Demographic Health Survey - The DHS Program is funded by the U.S. Agency for International Development (USAID), were excluded. Furthermore, only data from the DHS Program, which were not older than five years (2012- 2017) [20], were considered. To narrow down the comparator group, the low stigma index from under $20 \%$ was limited to between 13 and $17 \%$. As a result, eleven countries were selected as indicated in the flow chart (Figure 1 and Table 1): comprising eight countries with a high (Niger, Guinea, Ghana, Sierra Leone, Liberia, Mali, Togo Democratic Republic of Congo), and three countries (Rwanda, Zambia and Namibia) with a low stigma index.

From the received data of the DHS questionnaires, the phases 6 and 7 were chosen due to their currency. The 8 survey datasets were examined in regards with education and knowledge on the stigmatization of HIV/AIDS. The Individuals Recode (female dataset) and the Male Recode survey datasets, contain all the relevant questions to answer the leading item. Moreover, the questions were limited to topics on demographics ${ }^{\mathrm{a} 1}$, education ${ }^{\mathrm{b}} 2$ and specific knowledge ${ }^{\mathrm{c} 3}$ regarding HIV/AIDS and stigma ${ }^{\mathrm{d} 4}$. Altogether 33 questions were related to the topic. For 7 of those 33 questions, no answers were available which leaves 26 questions for further studies ( 8 for demographics, 2 for education, 12 on knowledge and 4 regarding stigma). Consequently, Zimbabwe was ruled out since the available data from the country answered only one question of the

\footnotetext{
$\mathrm{a}^{1}$ : the number and characteristics of people who live in a particular area or form a particular group, especially in relation to their age, how much money they have and what they spend it on [1]

$\mathrm{b}^{2}$ Knowledge and skills developed especially in school or college

$\mathrm{c}^{3}$ understanding of or information about HIV/Aids that you get by experience or study, either known by one person or by people generally[2]

$\mathrm{d}^{4}$ feelings of disapproval that people have about particular illnesses or ways of behaving [3]
} 
section on stigma. Given that the available comparator group was reduced only two countries, the low stigma index was readjusted to between 13 and $18 \%$ to include one more country. After reviewing the criteria, Zambia was chosen as the third country of comparison.

All the data were analyzed descriptively to identify the trends and their likely implications. For the data management

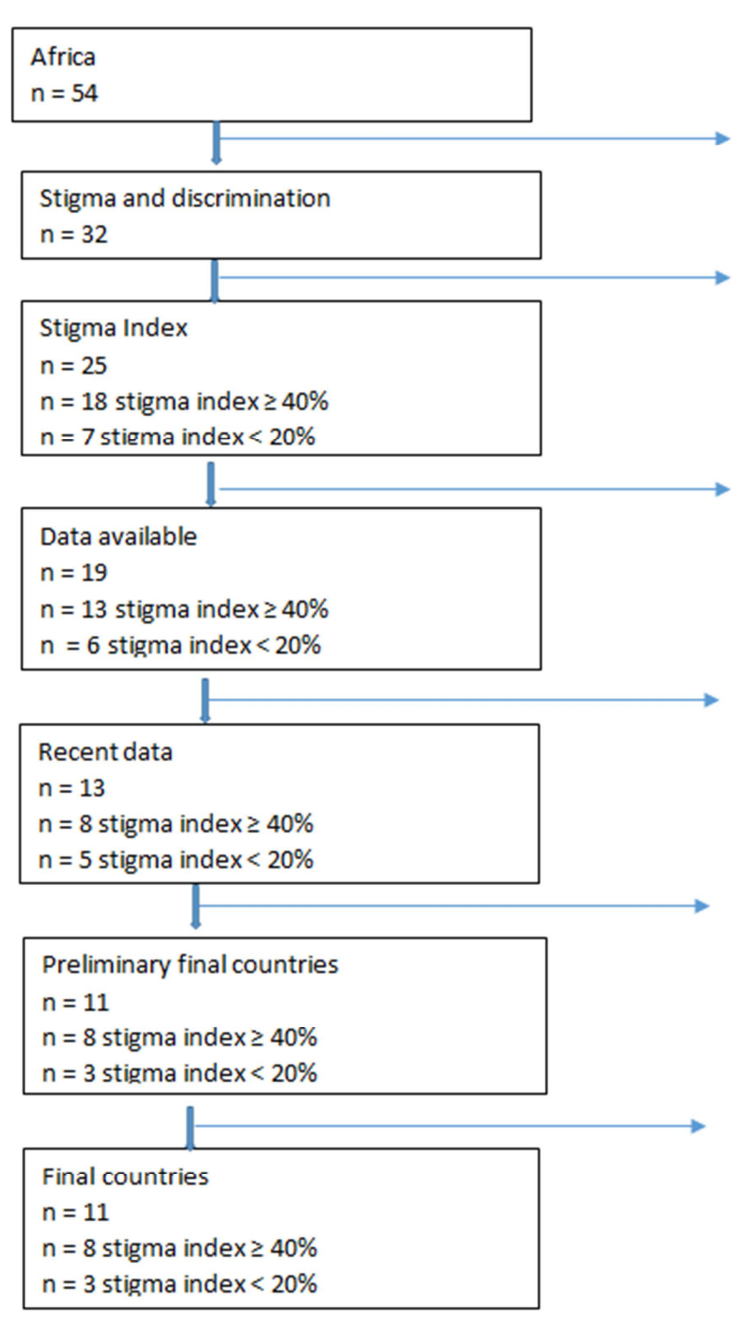

purposes, two calculation models were developed to classify knowledge and stigma tendency. A respondent that answered a given question correctly was given one point to signify knowledge, while a respondent that provided an incorrect answer or indicated that he or she did not know, was given the value zero to signify a lack of knowledge.

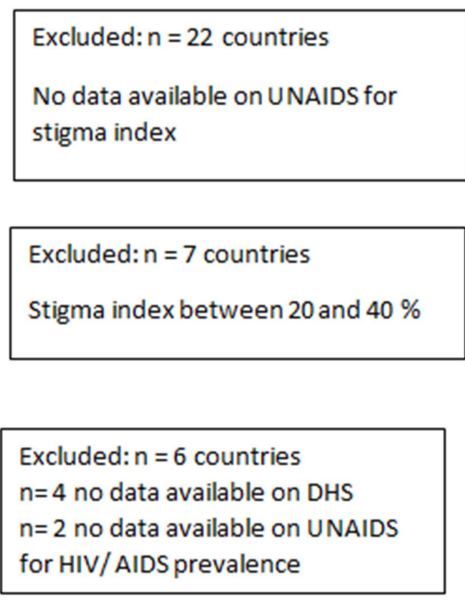

\section{Excluded: $n=6$ countries \\ No data surveyed in the last 5 years}

Excluded: $n=2$ countries

Stigma index $\geq 13$ AND $\leq 17 \%$

\section{Excluded: $\mathrm{n}=1$ country}

Only one question in the section

about stigma

Included: $\mathrm{n}=1$ country

Stigma index $\geq 13$ AND $\leq 18 \%$

Figure 1. Flowchart of the selection process.

Table 1. Selected countries.

\begin{tabular}{lllll}
\hline Type of group & Countries & $\begin{array}{l}\text { Stigma Index in \% } \\
\mathbf{( 2 0 1 5 )}\end{array}$ & $\begin{array}{l}\text { HIV Prevalence in \% Adults } \\
\mathbf{1 5 - 4 9}(\mathbf{2 0 1 5})\end{array}$ & $\begin{array}{l}\text { HIV Incidence in \% Adults } \\
\mathbf{1 5 - 4 9}(\mathbf{2 0 1 5})\end{array}$ \\
\hline & Niger & 71.5 & 0.05 & 0.02 \\
& Guinea & 80.1 & 1.60 & 0.12 \\
& Ghana & 67.7 & 1.60 & 0.08 \\
Observator & Sierra Leone & 53.4 & 1.30 & 0.07 \\
Group & Liberia & 52.7 & 1.10 & 0.06 \\
& Mali & 45.8 & 1.30 & 0.11 \\
& Togo & 45.8 & 2.40 & 0.12 \\
Comparator & Democratic Republic of Congo & 49.2 & 0.80 & 0.03 \\
Group & Zambia & 14.4 & 2.90 & 0.14 \\
& Namibia & 18.0 & 12.90 & 0.85 \\
\hline
\end{tabular}

Twelve questions were identified as investigating the respondents' knowledge on HIV. Since not all respondents answered all twelve questions, a variable was created containing the number of questions the respondent was 
actually asked. This variable was used to generate a value representing the percentage of correctly answered questions relative to the number of questions the respondent was asked. Based on the percentage of correctly answered questions, the respondent was placed in one of the four knowledge classes ( $\leq 25 \%$ class one, $>25 \% \leq 50 \%$ class two, $>50 \% \leq 75 \%$ class three, $>75 \%$ class four).

\subsection{Development of the Variables “Knowledge_Class" and "Stigma_Class"}

Four questions examining the respondent's attitude towards stigmatization of HIV-positive people were used to classify the respondent's tendency to stigmatize. Each answer showing a stigmatization of HIV-positive people contributed two points to the respondent's stigmatization rate. The answer "do not know" contributed one point to the respondent's stigmatization rate. Each answer proving a prejudice-free attitude contributed zero points. The stigmatization rate was divided by the number of answered questions to create a stigmatization score relative to the number of questions answered. Based on the result of this operation the respondent was classified as follows: $<0.5$ - class one defined as signifying little tendency to stigmatise; $0.5<1.0$ class two defined as signifying medium tendency to stigmatise; $1.0<1.5$ - class three defined as signifying high tendency to stigmatise, and $>1.5$ - class four defined as signifying very high tendency to stigmatise. The data from each country was characterized separately using IBM SPSS Software. The outcome of interest was the stigma tendency related to educational attainment, literacy, and the knowledge class. The data were evaluated by frequency tables and chi-square tests.

\section{Results}

\subsection{Educational Attainment and Tendency to Stigmatize}

The trends from the data suggest a negative association between educational attainment and stigmatization of people with HIV/AIDS, (Table 2). For instance, the countries with the highest number of illiterates - i.e. those without any form of education - Niger (70.6\%), Mali (70.3\%), Guinea (60.5\%), Sierra Leone (51.1\%), Liberia (32\%), Togo (29.3\%), Ghana (21\%) and Congo DR (13.5\%) - in descending order), had high stigma index $(>40 \%)$ unlike the three countries with the least number of illiterates, (Rwanda- $11.5 \%$, Namibia- $8.4 \%$ and Zambia-6.1\%), who accounted for the highest number of those with the least tendency to stigmatize HIV-infected people -i.e. Rwanda (56.4\%), Namibia (34.3\%) and Zambia (24.1\%) - in descending order. Nevertheless, further analysis showed a mixed result was observed among countries with the highest educational attainment in relation to a tendency to stigmatize. For instance, apart from Namibia (22.5\%), Congo DR has highest number $(17.7 \%)$ of those with complete secondary school and higher education, even greater than Zambia (17.3\%), yet Congo DR has a higher number (34.6\%) of those with the greatest tendency to stigmatize (i.e. class 4) HIV-infected people compared to either Zambia (5.2\%), Namibia $(2.5 \%)$ or Rwanda $(2.2 \%)$. A similar trend was obvious when Ghana (14.3\%), Sierra Leone (9.7\%), and Liberia $(9.2 \%)$ all of which have a higher number of such educated people than Rwanda (9.3\%), yet those with the greatest tendency to stigmatize were higher in the former countries $(30.8,24.5 \%$, and $50 \%)$ than the later $(2.2 \%)$.

Table 2. Overview of results in selected countries.

\begin{tabular}{|c|c|c|c|c|c|c|}
\hline & Congo, DR & Ghana & Guinea & Liberia & Mali & Namibia \\
\hline UNAIDS STIGMA & 49.2 & 67.7 & 80.1 & 52.7 & 45.8 & 13 \\
\hline Record & 2013 & 2014 & 2012 & 2013 & 2012 & 2013 \\
\hline Population & 72.550 .000 & 26.790 .000 & 11.630 .000 & 4.294 .000 & 16.110 .000 & 2.347 .000 \\
\hline Respondents & $0.04 \%$ & $0.05 \%$ & $0.11 \%$ & $0.31 \%$ & $0.09 \%$ & $0.62 \%$ \\
\hline \multirow{2}{*}{ Men } & 8656 & 4388 & 3782 & 4118 & 4399 & 4481 \\
\hline & $31 \%$ & $32 \%$ & $29 \%$ & $31 \%$ & $30 \%$ & $31 \%$ \\
\hline Women & $69 \%$ & $68 \%$ & $71 \%$ & $69 \%$ & $70 \%$ & $69 \%$ \\
\hline Urban & 35.8 & 48.3 & 39.6 & 39.8 & 31 & 50.9 \\
\hline Rural & 64.2 & 51.7 & 60.4 & 60.2 & 69 & 49.1 \\
\hline \multicolumn{7}{|l|}{ Education in \% } \\
\hline no Education & 13.5 & 21.3 & 60.5 & 32 & 70.3 & 8.4 \\
\hline incompl. Prim. & 26.5 & 12.5 & 12.3 & 30.9 & 8.3 & 17.3 \\
\hline comp. Prim. & 8.4 & 5.2 & 2.7 & 3.5 & 2.5 & 6.7 \\
\hline incompl. Sec. & 37.6 & 43.4 & 17.6 & 24.3 & 15.3 & 45.1 \\
\hline Higher & 4.3 & 7 & 4.9 & 3 & 2.3 & 7.5 \\
\hline \multicolumn{7}{|l|}{ Knowledge in \% } \\
\hline$<25$ & 3.5 & 2.9 & 5.1 & 9.5 & 17.1 & 1.1 \\
\hline $25-50$ & 61.3 & 8.6 & 13.3 & 31.8 & 13.2 & 3.5 \\
\hline$>50-75$ & 35.2 & 43.6 & 46.1 & 26.9 & 31.2 & 22.7 \\
\hline$>75$ & 0 & 44.9 & 35.5 & 31.7 & 38.4 & 72.5 \\
\hline \multicolumn{7}{|l|}{ Stigma in \% } \\
\hline class 1 & 4.8 & 10.9 & 6.1 & 4.6 & 10.5 & 34.3 \\
\hline class 2 & 32 & 28.2 & 20.7 & 10.2 & 42.8 & 52.5 \\
\hline class 3 & 28.6 & 30.1 & 32.1 & 35.2 & 24.6 & 10.7 \\
\hline class 4 & 34.6 & 30.8 & 41 & 50 & 22.1 & 2.5 \\
\hline
\end{tabular}


Table 2. Continued.

\begin{tabular}{|c|c|c|c|c|c|}
\hline & Niger & Ruanda & Sierra Leone & Togo & Zambia \\
\hline UNAIDS STIGMA & 71.5 & 14.40 & 53.4 & 45.8 & 18 \\
\hline Record & 2012 & 2014 & 2013 & 2013 & 2013 \\
\hline Population & 17.640 .000 & 11.340 .000 & 6.179 .000 & 6.929 .000 & 15.250 .000 \\
\hline \multirow{2}{*}{ Respondents } & 15088 & 19714 & 23947 & 13956 & 31184 \\
\hline & $0.09 \%$ & $0.17 \%$ & $0.39 \%$ & $0.20 \%$ & $0.20 \%$ \\
\hline \multirow{2}{*}{ Men } & 3928 & 6217 & 7262 & 4476 & 14773 \\
\hline & $26 \%$ & $32 \%$ & $30 \%$ & $32 \%$ & $47 \%$ \\
\hline \multirow{2}{*}{ Women } & 11160 & 13497 & 16685 & 9480 & 16411 \\
\hline & $74 \%$ & $68 \%$ & $70 \%$ & $68 \%$ & $53 \%$ \\
\hline Urban & 31.6 & 25.5 & 40.8 & 37.1 & 47.1 \\
\hline Rural & 68.4 & 74.5 & 59.2 & 62.9 & 52.9 \\
\hline \multicolumn{6}{|l|}{ Education in \% } \\
\hline no Education & 70.6 & 11.5 & 51.1 & 29.3 & 6.1 \\
\hline incompl. Prim. & 12.3 & 41.9 & 8.4 & 23.2 & 27.7 \\
\hline comp. Prim. & 2.3 & 21.4 & 4.8 & 7 & 16.1 \\
\hline incompl. Sec. & 12.5 & 15.9 & 26 & 34.3 & 32.9 \\
\hline comp. Sec. & 0.5 & 5.5 & 5.9 & 2 & 10.7 \\
\hline Higher & 1.7 & 3.8 & 3.8 & 4.2 & 6.6 \\
\hline \multicolumn{6}{|l|}{ Knowledge in \% } \\
\hline$<25$ & 12.5 & 0.1 & 7.1 & 2.8 & 0.5 \\
\hline $25-50$ & 15.8 & 0.4 & 13.5 & 6.8 & 3 \\
\hline$>50-75$ & 38.9 & 9.1 & 38.9 & 39.3 & 29.5 \\
\hline$>75$ & 32.9 & 90.4 & 40.5 & 51 & 67 \\
\hline \multicolumn{6}{|l|}{ Stigma in \% } \\
\hline class 1 & 9.2 & 56.5 & 6.8 & 12.8 & 24.1 \\
\hline class 2 & 26.6 & 35.1 & 36.5 & 41.4 & 55.7 \\
\hline class 3 & 30.3 & 6.2 & 32.2 & 25.1 & 15 \\
\hline class 4 & 33.8 & 2.2 & 24.5 & 20.7 & 5.2 \\
\hline
\end{tabular}

\subsection{Association of Stigma Class and Knowledge Class}

There was a common trend observed, for all analyzed countries, when stigma class and knowledge class were correlated. For instance, there was an inverse proportional relationship between stigma class and knowledge class about HIV/AIDS (Table 2) in countries with a high stigma index (Niger, Mali, Guinea, Sierra Leone, Liberia, Togo, Ghana and Congo DR). The same trend was recognizable for countries with a low stigma index (Table 2) when the knowledge class and stigma class are correlated - Rwanda (90.4\%/2.2\%), Namibia (72.5\%/2.5\%) and Zambia (67\%/5.2\%).

\subsection{Educational Attainment and Knowledge of HIV/AIDS}

Available data were evaluated to determine whether people who are better educated have a greater knowledge about HIV/AIDS than people who are poorly educated. The findings showed that with higher education, there was more knowledge about HIV/AIDS. Though about $8.3 \%$ of the respondents with higher education have a poor or medium knowledge about HIV/AIDS, the majority $(91.7 \%)$ of the respondents with a higher education have a high or even very high knowledge about the disease. This is consistent with the country specific analysis (Table 2), which showed that Rwanda, Namibia, and Zambia (i.e. the countries with the least number of illiterates), also had the highest level of knowledge about HIV/AIDS in descending order. The comparator group proves this given that only $0.3 \%$ of the respondents with a higher educational attainment had the poor or medium knowledge, whereas $99.7 \%$ had high and very high knowledge. However, contrary to expectation. it was shown that the highest number of those with a poor or medium knowledge about HIV/AIDS were not those without any education but those who had primary school education. They also had the least number of those with high or very high knowledge about the disease.

\subsection{Urban/rural Areas and Knowledge of HIV/AIDS}

Available data was analyzed to determine whether people living in urban areas have greater knowledge about HIV/AIDS than people living in rural areas. Focusing on the differences between the living/residential areas, it was shown that in the urban areas, there was an appreciable knowledge of HIV - mostly rated high and very high. This trend was applicable to countries with low and high stigma index, respectively. However, the gap in knowledge about HIV was wider between the urban and rural areas in countries with high stigma index $(15.8 \%)$ (Table 3 ) than those with low stigma index (1.5\%) (Table 4) when those with high and very high knowledge of HIV are considered.

Table 3. Correlation of type of place of residence and knowledge $(N=8)$.

\begin{tabular}{lll}
\hline High stigma countries & Knowledge 0-50\% & Knowledge $>\mathbf{5 0 - 1 0 0 \%}$ \\
\hline Urban & $19.7 \%$ & $80.3 \%$ \\
Rural & $35.5 \%$ & $64.5 \%$ \\
\hline
\end{tabular}

Table 4. Knowledge of HIV in urban versus rural areas in low stigma countries $(N=3)$.

\begin{tabular}{lll}
\hline Low stigma countries & Knowledge $\mathbf{0 - 5 0 \%}$ & Knowledge $>\mathbf{5 0 - 1 0 0 \%}$ \\
\hline Urban & $2.0 \%$ & $98.0 \%$ \\
rural & $3.5 \%$ & $96.5 \%$ \\
\hline
\end{tabular}


This trend was even more established with increasing educational attainments. However, in the rural areas of countries with high stigma index, most respondents possessed medium knowledge of HIV. The comparator group showed little differences between the urban and rural areas. A sub-analysis of the available data further showed that of the people living in urban areas of countries with high stigma index, $43.3 \%$ had a knowledge rating $>75 \%$ about $\mathrm{HIV}$, $37.0 \%$ were part of the third knowledge class $(>50-75 \%)$, $17.1 \%$ knew between $25-50 \%$ and $2.6 \%$ belonged to the first knowledge class $(<25 \%)$. Of the people living in rural areas $27 \%$ had a knowledge rating $>75 \%$ about HIV, $37.5 \%$ knew between $50-75 \%, 25.3 \%$ knew between $25-50 \%$ and $10.2 \%$ knew less than $25 \%$. In total, the knowledge about HIV was high but much higher in urban areas compared to rural areas.

The sub-analysis of the gender groups shows the same tendencies consistent with the general trends. Overall, the males in urban areas who have a high knowledge of HIV were more in proportion than the males in the rural areas who fall into a comparable class. For instance, of all urban males (Table 5) in countries with high stigma index, $81.6 \%$ had a knowledge between 50-100\% (comprising: $40.7 \%$ with a knowledge rating $>75 \%$ and $40.9 \%$ between $50-75 \%$ ). Of all rural males, $69.6 \%$ had a knowledge between $50-100 \%$ (comprising $28.6 \%$ with a knowledge rating $>75 \%$ and $41.0 \%$ between $50-75 \%$ ). A similar trend was recognized among the females when the urban and rural areas were compared. Thus, of all urban females, $79.8 \%$ had a knowledge between 50-100\% (comprising: $44.5 \%$ with a knowledge rating $>75 \%$ and $35.5 \%$ between $50-75 \%$ ). Of all rural females, $62.2 \%$ had a knowledge between $50-100 \%$ (comprising 26.3\% with a knowledge rating $>75 \%$ and $35.9 \%$ between $50-75 \%$ ). However, a comparison between both genders across urban and rural areas showed that whereas the proportion of the females with a high knowledge of HIV was higher than males in the urban areas, the exact opposite was observed in the rural areas. Country-specific analysis showed no significant difference between the eight selected countries with a high stigma index.

Table 5. Knowledge of HIV across sex and urban/rural area in high stigma countries $(N=8)$.

\begin{tabular}{llll}
\hline \multicolumn{2}{l}{ High stigma countries } & Knowledge 0-50\% & Knowledge $>\mathbf{5 0 - 1 0 0 \%}$ \\
\hline \multirow{2}{*}{ Urban } & male & $18.4 \%$ & $81.6 \%$ \\
& female & $20.1 \%$ & $79.8 \%$ \\
\multirow{2}{*}{ Rural } & male & $30.4 \%$ & $69.6 \%$ \\
& female & $37.7 \%$ & $62.2 \%$ \\
\hline
\end{tabular}

In broad terms, the people living in urban areas (Table 6), in countries with low stigma index, comprised $98 \%$ with a knowledge rating between $>50-100 \%$ about HIV. This includes about $78.0 \%$ had a knowledge rating $>75 \%$ about HIV, 20.0\% know between 50-75\%, 1.7\% know between 25 $50 \%$ and $0.3 \%$ know less than $25 \%$. Of the people living in rural areas $73.4 \%$ had a knowledge rating $>75 \%$ about $\mathrm{HIV}$, $23.1 \%$ know between $50-75 \%, 2.8 \%$ know between $25-50 \%$ and $0.7 \%$ know less than $25 \%$. Independent of residence and sex, at least $67.3 \%$ of the respondents in each group (i.e. countries with high and low stigma index) were in the knowledge class 4 with more than $75 \%$ of correctly answered questions (including $67.3 \%$ rural males, $71.7 \%$ urban males, $77.2 \%$ rural females and $82.1 \%$ urban females). Countryspecific analysis showed that the knowledge of HIV varies in the three selected countries with a low stigma index. In Rwanda, the knowledge about HIV was conspicuously high such that $93.1 \%$ of the people living in urban areas and $89.5 \%$ in the rural areas, had a knowledge rating $>75 \%$. In comparison, Zambia showed significantly lower knowledge with only $73.5 \%$ of the people living in urban areas and $61.2 \%$ of the rural population falling within the knowledge class 4.

Sub-analysis of the sex differences with regards to knowledge of HIV across urban and rural areas, in countries with a low stigma index, showed that of all urban males (Table 6), 97.6\% had a knowledge between 50-100\% (comprising $71.7 \%$ with a knowledge rating $>75 \%$ and $25.9 \%$ between $50-75 \%$ ). Of all rural males, $95.9 \%$ had a knowledge between 50-100\% (comprising 67.3\% with a knowledge rating $>75 \%$ and $28.6 \%$ between $50-75 \%$ ). Of all urban females, $98.3 \%$ had a knowledge between $50-100 \%$ (comprising $82.1 \%$ with a knowledge rating $>75 \%$ and $16.2 \%$ between $50-75 \%$ ). Of all rural females, $96.9 \%$ had a knowledge between $50-100 \%$ (comprising $77.2 \%$ with a knowledge rating $>75 \%$ and $19.7 \%$ between $50-75 \%$ ). The overall significant trend is that distinguish countries with high stigma index from those with low stigma index is that the knowledge of HIV in both the urban and rural areas was greater among women compared to men in the later than the former.

Table 6. Knowledge of HIV across sex, urban versus rural areas in low stigma countries $(N=3)$.

\begin{tabular}{llll}
\hline \multicolumn{2}{l}{ Low stigma countries } & Knowledge 0-50\% & Knowledge $>\mathbf{5 0 - 1 0 0 \%}$ \\
\hline \multirow{2}{*}{ Urban } & male & $2.4 \%$ & $97.6 \%$ \\
& female & $1.8 \%$ & $98.3 \%$ \\
\multirow{2}{*}{ Rural } & male & $4.1 \%$ & $95.9 \%$ \\
& female & $3.1 \%$ & $96.9 \%$ \\
\hline
\end{tabular}

\subsection{Association Between Knowledge Class and Social Stigmatization}

The question of whether increasing level of knowledge about HIV/AIDS also has a more positive attitude towards those infected by HIV, in a manner that discourages social stigmatization was probed with the following questions: - $A$ female teacher infected with HIV, but is not sick, should be allowed to continue teaching?"

In countries with a high stigma index, (Table 7) the respondents who fall within the knowledge rate $>75 \%$, would accept an infected teacher much more often than those with a knowledge rating of $25-50 \%$. Approximately $91.87 \%$ of the respondents within the knowledge group rated $>75 \%$, gave a positive answer to the question. However, only $77.78 \%$, within the third knowledge group answered positively (i.e. "Yes"), when asked the same question. Within the knowledge class two $(25-50 \%) 59.57 \%$ of the respondents stated that a 
female teacher should be allowed to continue teaching. In contrast, $31.68 \%$ of the knowledge rate of $<25 \%$, answered positively. In comparison, data from the countries with a low stigma index showed that in the fourth knowledge class (>75\%), approximately $92 \%$ responded positively to the question. Although significantly more data of women were collected than of men. Approximately $91 \%$ of women in the class with a knowledge rate $>75 \%$ would accept an HIVinfected teacher compared to $88 \%$ of men in the comparable class. Overall, men and women in the countries with a high stigma tendency showed slight differences in allowing an HIV-infected female teacher to continue teaching: About $71 \%$ of the men in the fourth knowledge group (>75\%) would accept the said teacher, just like only $68 \%$ of the women. However, there were twice as many women respondents than men. Generally, countries with a low stigma index hardly showed any differences between men and women.

Furthermore, it was examined whether the residential situation of the respondents had an influence on their stigma tendency. It is shown (Table 7) that people from a country with high stigma tendency, and in urban areas, had a more positive attitude towards the teacher than the people living in rural areas: around $76 \%$ of the respondents lived close to the city, and who had a knowledge rating $>75 \%$, responded positively for the teacher to be allowed to continue teaching, whereas only $59 \%$ of people living in rural areas, in the same category, thought the same. Even under the influence of the residential situation, the countries with a low tendency to stigmatize showed a more positive attitude: approximately $95 \%$ of those who lived in an urban area and had a knowledge rate $>75 \%$ had a positive attitude towards the teacher, likewise $89 \%$ of those who live in rural areas. Despite the different variables (sex/residential situation), there is a clear trend which shows that the higher the knowledge about HIV/AIDS, the lower is the tendency to stigmatize.

Table 7. Respondents attitude to an HIV-infected teacher across residential area in relation to the level of stigma and knowledge rate.

\begin{tabular}{lll}
\hline High stigma - & \multicolumn{2}{l}{ Type of Place of residence } \\
\cline { 2 - 3 } Knowledge rate & Urban & Rural \\
\hline$<25 \%$ & $21.58 \%$ & $16.70 \%$ \\
$25-50 \%$ & $47.08 \%$ & $31.69 \%$ \\
$>50-75 \%$ & $62.15 \%$ & $42.62 \%$ \\
$>75 \%$ & $75.23 \%$ & $59.26 \%$ \\
\hline
\end{tabular}

\subsection{Association Between Knowledge Class and Physical Stigmatization}

The question of whether increasing level of knowledge about HIV/AIDS also has a more positive attitude towards those infected by HIV, in a manner that discourages physical stigmatization was probed with the question: -"would you buy vegetables from a vendor with HIV?"Data showed that the higher the knowledge about HIV/AIDS, the more the respondents are willing to buy vegetables from a vendor who is infected with HIV. In the first knowledge class, $(<25 \%$ knowledge) $11.1 \%$ of those interviewed, indicated that they would go grocery shopping there. The amount of those who would buy vegetables from an $\mathrm{HV}$-infected vendor increases proportionally to the level of knowledge. In the fourth knowledge class $(>75 \%$ knowledge $) \quad 53.4 \%$ of the respondents gave a positive answer to the question.

Countries with a low stigma index showed as well, that people with a higher knowledge about HIV/AIDS tend to have a more positive view of HIV infected people. Within the first knowledge class, $35.6 \%$ of those interviewed replied that they would buy from an infected greengrocer. Nevertheless, in the fourth knowledge class, $88.7 \%$ answered positively. In comparison to the countries with a high stigma index, significantly more respondents would be willing to buy vegetables from a vendor who is HIV infected. Among the countries, obvious differences can be recognized. For example, in Guinea and Ghana, it was shown that only a few respondents even in the fourth knowledge class would buy vegetables from an infected vendor (34.8\%/ 42.1\%). In Sierra Leone and Mali, however, the respondents answered more positively (60.4\%/ 67.1\%). There are no obvious recognizable country-country differences among nations with a low stigma index.

Data showing sex differences in all knowledge classes, from countries with high stigma index, men were rather willing to buy vegetables from a vendor who is infected with HIV than women. This disparity is especially striking in the third knowledge class ( $>50-75 \%$ knowledge), where $35.8 \%$ of the women compared to $43.1 \%$ of the men answered the question positively. Data from the comparator group showed that also in countries with a lower stigma index, men were rather willing to buy vegetables from an infected vendor than women.

Interviewees living in urban regions were more likely/willing to go shopping at an HIV infected vendor, than those living in rural regions. Within the fourth knowledge class, $61.3 \%$ of people living in urban regions and $45.7 \%$ of those living in rural areas, stated that they would buy from an HIV-Infected vendor. Thus, even in the highest knowledge class, less than half of those interviewed, who were living in rural areas answered positively. Respondents from urban areas in the countries with a low stigma index rather answered positively than those from rural areas. However, the differences were as significant as among the countries with a high stigma index. In the knowledge class rated $>75 \%$, approximately $91 \%$ of the respondents living in urban areas answered the same question positively than $87 \%$ who responded likewise from the rural areas.

\subsection{Knowledge of Transmission of HIV and Social Stigmatization}

Available data from countries with high stigma index was explored to determine whether a belief that HIV/AIDS can be transmitted by sharing food will influence their attitude towards buying vegetables from an infected vendor. Overall, the respondent's answers to questions bothering on knowledge of HIV transmission and tendencies to stigmatize 
were cross-matched (Table 8) to see if there were connections between both factors. Generally, it was shown that only half of those who indicated that HIV cannot be transmitted by sharing food with an infected person, were also willing to buy their grocery from an infected person. In contrast, the majority of those who indicated that HIV can be transmitted by sharing food with an infected person, was also not willing to buy their grocery from an infected individual. The majority of those who do not know whether HIV can be transmitted by sharing food with an infected person also indicated an unwillingness to buy their grocery from an infected grocer.

Table 8. Respondents attitude to an HIV-infected vendor in relation.

\begin{tabular}{|c|c|c|c|c|c|}
\hline & & \multicolumn{4}{|c|}{ Would buy vegetables from Vendor with HIV } \\
\hline & & No & Yes & Don't know & Total \\
\hline Can get HIV by sharing & No & $48 \%$ & $50.80 \%$ & $1.00 \%$ & $100.00 \%$ \\
\hline food with person who & Yes & $77.40 \%$ & $21.90 \%$ & $0.70 \%$ & $100.00 \%$ \\
\hline has AIDS & Don't know & $74.00 \%$ & $18.30 \%$ & $7.60 \%$ & $100.00 \%$ \\
\hline
\end{tabular}

\section{Discussion}

It was obvious that stigma has remained highly significant in the context of HIV /AIDS, in many African countries, and supports a previous view. [21] Available data suggest that although the tendency to stigmatize HIV-infected people was evident across African countries with a high and low stigma index, but it was greater in the former than the later. The tendencies to stigmatize was associated with the level of education and knowledge about HIV/AIDs among the populace.

However, there were noticeable inclination for HIVinfected people to be physically stigmatized than to be socially stigmatized. This is evident in the observed tendencies of the respondents to stigmatize and discriminate against teachers and grocers, who are infected with HIV. However, more respondents have positive attitude towards the teacher who basically fulfills a social function than to physically interact or buy vegerables from an a HIV-infected grocer. These two events represent social and physical forms of stigmatization. The physical stigma is evident when HIVnegative individuals do not want to sleep, share meal, or drink from the same cup, with people known to be HIV positive, [3] as also applicable with the greengrocer. Thus, half of those who indicated that HIV cannot be transmitted by sharing food with an infected person, still indicated that they will not patronise a greengrocer who is HIV positive. Moral stigma has a tendency to be linked to physical stigma and it is possible that it is the cause of physical stigma.[3] Other authors also express the view that social stigma does not exist in isolation in any community rather it is interconnected with moral and physical stigma. [21,23] Of all these, physical discrimination represents the worst type of discrimination in African communities "due to the immoral perception of HIV patients as being promiscuous, unfaithful to their partners and being rebuffed by God as a consequence of their immorality. "[3]

In this context, the respondents' attitude towards HIVinfected people in this study may derive from a moral persuasion that they are unfit as role models for school children since HIV transmission has been associated with morally reprehensible acts. This mindset seems to feed and inform the basis for moral stigmatization that may give rise to social and physical stigmatization.
Admittedly, people living in urban areas preferably would want an HIV infection in their family to remain secret and also more of the interviewed subjects agreed with the infected teacher continuing to work compared to the number of those, who would buy vegetables from an HIV-positive vendor. But the interviewed subjects answered the questions in an inconsistent manner. For instance, a lot of people would be willing to buy vegetables from the vendor but would not share food with someone who is infected with HIV. There could also be other sides to the storyit is possible that sociocultural factors maty mediate the tendencies to stigmatize, isolate and limit most forms of communal relationships with individuals infected with HIV. This could be possibly out of fear or ignorant assumption that sharing of food might contaminate the food item and transmit the disease. In addition, the observed trends may also suggest that people do respond differently to $\mathrm{HIV}$-infected individuals considering the proximity of their interaction with the person. The chances of proximate personal contact/interaction with "an infected teacher" seem to weigh less compared to "HIVinfected food vendor." Therefore, it appears that the respondents seemed more skeptical, the greater their proximity with the HIV-infected person.

Whatever may be the reasons for stigmatization, there is no denying the facts that the tendency to disapprove the retention of the services of a teacher or patronage of a greengrocer just for being HIV-infected may have adverse effects on the well-being of the infected people. Currently, there are reports that HIV/AIDS-related stigma and discrimination have led to job and lodge losses as well as difficulty in accessing healthcare and education among people living with the virus. [3] Therefore, it is reasonable to expect that HIV /AIDS-related stigma may compromise the well-being of people living with the disease and may adversely affect current efforts to contain the spread of the disease. This is reasonable because most infected people are likely to live in self-denial considering the damaging effects of stigmatization if their status were to be disclosed. This may mean that most people are less likely to uptake HIV screening tests or openly attend HIV clinics for supportive care. The broad picture from this study may also imply that since the tendency to stigmatize is higher in rural areas of Africa than the urban areas, the net effect should suggest that HIV spread in rural communities may continue unabated. 
Moreover, since the majority of African countries are listed as having a high stigma index, the continent may continue to have a bleak outlook in containing the spread of the disease as well until stigmatization is addressed.

Interestingly, the available evidence from this study indicates that the tendency to stigmatize/discriminate against HIV-infected people was positively influenced with increasing level of education and knowledge of HIV in most African countries. It appears that the most important impact factors of positive attitudes towards HIV-infected people are education and knowledge about HIV. It was revealed that the higher a person's educational attainment, the greater the possibility of a change in attitude towards HIV-infected people. It seems that a higher educational attainment proportionately translates into a higher knowledge about HIV/AIDS, and an improved disposition towards HIVrelated issues or/and $\mathrm{HIV}$-infected people. Invariably, education and knowledge of HIV may act as important suppressor variables which might serve as effective tools against HIV/AIDs-related stigmatization. These findings do not, however, suggest that education and knowledge of HIV/AIDS are sufficient conditions for positive behavioral change towards HIV-infected people/issues. On the contrary, they seem to be necessary conditions that give impetus for the realization of the desired positive change. This view agrees with previous authors. [25, 26]

Sub-group analysis provided some interesting pictures that further highlight the role or influence of environment, culture, and socialization on education and knowledge about HIV/AIDs in mitigating stigmatization/discrimination against the HIV-infected people. Thus, it was revealed that the urban dwellers had a higher level of education and knowledge about HIV/AIDS than the rural dwellers. This was not surprising, because urban areas in Africa are mainly egalitarian communities, and their cosmopolitan nature signposts them as the melting pots of diversities, information, education, and civilization, which contrasts sharply with the rural areas. [26] In fact, the rural areas in Africa are known to be more conservative settings, which are mainly plagued by a high level of illiteracy and populated by poverty-stricken cultural communities. [26] Therefore, the expectation was that these two contrasting environments will influence the respondents' disposition towards HIV-infected individuals in a manner that is diametrically opposite. This expectation was confirmed considering that a higher level of education and knowledge about HIV/AIDs was observed among urban than rural dwellers, likewise the decreased tendencies to stigmatize HIV-infected people.

Perhaps, congruent to the environmental influences on education and knowledge of HIV/AIDs, is the influence of gender role in cultural communities of Africa, [27, 28] which creates gender inequalities, with respect to education and empowerment of women than men. [29, 30] Therefore, illiteracy, ignorance and subservient cultural views of are likely to be a commonplace among women in the mostly male-dominated African societies. The men being at a greater advantage are more likely to be more educated or at least more empowered to get such education than women. This might explain why the men had more positive attitudes toward HIV-infected people. However, the fact that this trend persists even when the men belonged to the same knowledge class as the women may be a function of the cultural role of women as teachers/propagators of cultural belief, [31, 32] which negates progressive values and entrenches conservative norms. The cultural role of women as traditional teachers, educators and drivers of social orientation seem to be the critical game changer that transformed and made thedifference between countries with high stigma index than low stigma index. This is plausible, because in the only distinguishing features between these countries is that in countries with low stigma index, women were more educated than men in both urban and rural communities. Similarly, women were more knowledgeable than men about HIV/AIDs in both the urban and rural communities. This contrasts with the conservative roles played by women in countries with high stigma index where the educated and knowledgeable women are in the minority compared to the men. Therefore, it may be unreasonable to conclude that men are more positive towards HIV-infected individuals than women without putting the proportion of the educated women into context. Given this narreative, it might be reasonable to sugest that the fight against stigmatisation of HIV-infected people may receive additional boost back in most parts of Africa when women are educated and availed the necessary know; edge about such health issues.

In the countries with a low stigma index, the same trend could be shown, but even better. The people tend less often to discriminate against HIV-infected people. Compared to the countries with a high stigma index, the educational level is very high and the rate of illiteracy is low. But also, it can be seen, that these countries with a low-stigma index are also known to have a high prevalence of HIV infection. (Rwanda: 2.9\%, Namibia: $13.3 \%$, Zambia: $12.9 \%$ ). It could be that in those high prevalence settings, the disease could be considered more normal or that there has been more preventive measures and education to enlighten the people about HIV infection and therefore contribute to its prevention likewise their attitude towards the infected people, hence the low stigma index. Nevertheless, it was revealed that persons with a limited knowledge about HIV transmission, are more likely to discriminate and stigmatize HIV-infected people. So, they would less often buy vegetables from a vendor with HIV or would allow an infected female teacher to continue teaching. Furthermore, they would want to less often disclose an HIV infection in the family or are willing to care for a relative with HIV.

Perhaps, the tendency to live in denial of HIV infection within the family could be a response to anticipated negative socio-cultural experiences such as stigmatization, which may affect how the entire family members are perceived by the community. It seems to give credence to the view that that people are afraid of being stigmatized by the disclosure of an infection in a family or the caring for an infected person. Also, the lack of knowledge about HIV transmission could 
cause fear that the disease may be contagious and could be a reason for negative responses towards the infected people. However, it does not preclude the fact that there could be more socio-cultural drivers of HIV-related stigma and discrimination in African countries other than education and knowledge of HIV infection. For example, among all people who knew that HIV cannot be transmitted by sharing food, nearly the half of them would not buy vegetables from a vendor with HIV. The reasons may, therefore, be attributed to other factors other than education and knowledge of HIV. Nevertheless, this study revealed the importance of education and knowledge in the prevention of stigma associated with HIV in cultural communities. Education and knowledge about transmission and handling of HIV could, therefore, be the basis for a tolerant and open society, which is concerned to get this epidemic disease under control.

\section{Limitations of study}

The findings of this study only suggest the possibility of an association between education and knowledge about HIV/AIDS and stigmatization. Notwithstanding these findings, the cross-sectional nature of the data cannot be used to show causal claims. The descriptive statistics employed in the analysis of its findings do not support significant conclusions to be drawn from the results in the light of its statistical limitations.

Having analyzed other questions in details resulted in the following observations:

1. That the knowledge of HIV varied in the selected countries. For instance, in Rwanda, $93.1 \% / 89.5 \%$ of the urban/rural dwellers had a knowledge rating $>75 \%$ (i.e. 4th/highest knowledge class). In Zambia, only $73.5 \% / 61.2 \%$ of the urban/rural dwellers were in a comparable class.

2. However, only $<50 \%$ of the respondents in Guinea and Ghana $(34.8 \% / 42.1 \%)$, even in the 4 th class, showed the least tendency to stigmatize compared to $>50 \%$ from Sierra Leone and Mali $(60.4 \% / 67.1 \%)$, whereas there were no country-country differences among nations with a low stigma index.

3. In all knowledge classes, men were less inclined to stigmatize than women, and were rather willing to care for their relatives than women

4. More of the interviewed respondents expressed positive views about having an HIV-infected teacher continuing to work compared to the number of those who would buy vegetables from an HIV-positive vendor. This showed a greater tendency to physical stigmatization than social stigmatisation and seem to buttress the impact of physical contact and notion of contagious transmission of the disease on stigmatization.

5. Knowledge of the mode of transmission of HIV does not influence tendency to stigmatize in half of the population in countries with a high stigma index

6. The overall significant trend that distinguished countries with a high stigma index from those with low stigma index is that the knowledge of HIV in both the urban and rural areas was greater among women compared to men in the later than the former.

\section{Conclusion}

Investigation between countries and within-countries, across several sub-groups, such as urban and rural population, and sex, concluded in notable differences. Overall, urban-rural inequalities, gender roles and responsibilities of women, and illiteracy appear as important factors that may be associated with stigmatization of HIV-infected people in some African countries and should be targeted to reverse the trends. Importantly, education and knowledge of HIV/AIDS were identified as important factors that will postively influence stigmatizatiom of the infected people. But the fact that stigmatization also persists despite high education and knowledge in certain countries, lends credence to the view that there must be other impact factors at play, which should serve as an orientation for further studies.

\section{Acknowledgements}

We wish to acknowledge the sources of the dataset UNAIDS and the DHS Program (Demographic Health Survey - The DHS Program is funded by the U.S. Agency for International Development (USAID).

\section{Conflict of Interest}

The Authors declare that there is no conflict of interest

\section{Funding}

This research received no specific grant from any funding agency in the public, commercial, or not-for-profit sectors

\section{References}

[1] UNAIDS, $2016 \mathrm{http}: / / w w w . u n a i d s . ~ o r g / s i t e s /$ default/files/media_asset/UNAIDS_FactSheet_en.pdf

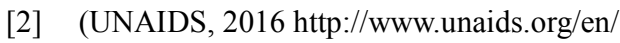
regionscountries/countries/

[3] Amuche NJ, Emmanuel EI, Innocent NE. HIV/AIDS in subSaharan Africa: Current status, challenges and prospects. Asian Pacific Journal of Tropical Disease. 2017; 7(4): 239256. https://doi.org/10.12980/apjtd.7.2017D6-366

[4] Food and Agricultural Organisation of the United Nations. AIDS - a threat to rural Africa. http://www.fao.org/FOCUS/E/aids/aids1-e.htm Accessed on 18/07/2017.

[5] Apanga PA. HIV/AIDS-related stigma and discrimination in sub-Saharan Africa: a review. J Nat Sci Res 2014; 4(21): 41-8.

[6] Obeng-Odoom F. The State of African Cities 2008: A framework for addressing urban challenges in Africa, edited by Alioune Badiane. Nairobi: UN-Habitat, 206 pp. ISBN 978 921132015 2. Afr Aff (Lond) (2010) 109 (435): 340-341. DOI: https://doi.org/10.1093/afraf/adq012 
[7] Ramin B. Slums, climate change and human health in subSaharan Africa. Bulletin of the World Health Organization. 2009 Dec;87(12):886-A.

[8] Colclough C, Rose P, Tembon M. Gender inequalities in primary schooling: The roles of poverty and adverse cultural International Journal of Educational Development. 2000 Jan $31 ; 20(1): 5-27$.

[9] Saleh, Adam Gambo and Lasisi, Fatima Ibrahim (2011). Information needs and information seeking behavior of rural women in Borno state, Nigeria. Library Philosophy and Practice (e-journal), accessed July 18, 2017, from http://www.webpages.uidaho.edu/ mbolin/saleh-lasisi2.htm

[10] Ogunsola LA. Health information literacy: a road map for poverty alleviation in the developing countries. Journal of Hospital Librarianship. 2009 Jan 16;9(1):59-72.

[11] Mufune P. Poverty and HIV/AIDS in Africa: specifying the connections. Soc Theory Health 2015; 13(1): 1-29.

[12] Ucha C. Poverty in Nigeria: Some dimensions and contributing factors. Global Majority E-Journal. 2010 Jun;1(1):46-56.

[13] De-Graft Aikins A, Marks DF. Health, disease and healthcare in Africa. Journal of Health Psychology. 2007 May;12(3):387402.

[14] Chaudhury N, Hammer J, Kremer M, Muralidharan K, Rogers FH. Missing in action: teacher and health worker absence in developing countries. The Journal of Economic Perspectives. 2006 Mar 1; 20(1):91-116.

[15] Ibeneme S, Eni G, Ezuma A, Fortwengel G. Roads to Health in developing countries-Understanding the intersection of culture and healing. Current Therapeutic Research. 2017 Mar 4.

[16] Mall S, Middelkoop K, Mark D, Wood R, Bekker LG. Changing patterns in HIV/AIDS stigma and uptake of voluntary counselling and testing services: the results of two consecutive community surveys conducted in the Western Cape, South Africa. AIDS Care 2013; 25(2): 194-201.

[17] Tsai AC, Hatcher AM, Bukusi EA, Weke E, Hufstedler LL, Dworkin SL, Kodish S, Cohen CR, Weiser SD. A livelihood intervention to reduce the stigma of HIV in rural Kenya: longitudinal qualitative study. AIDS and Behavior. 2017 Jan 1;21(1):248-60.

[18] Smith EA, Miller JA, Newsome V, Sofolahan YA, Airhihenbuwa CO. Measuring HIV/AIDS-related stigma across South Africa: a versatile and multidimensional scale. Health Educ Behav 2014; 41(4): 387-91.

[19] Thai Network of People Living with HIV/AIDS (TNP+) Index of stigma and discrimination against people living with HIV/AIDS in Thailand. 2009. [cited 2013 Jul 8]. Available from:http://www.aidsdatahub.org/dmdocuments/Stigma_Index -Thailand.pdf
[20] The DHS Program User Forum: HIV/AIDS » Stigma and Discrimination. The new questions suggested as well as the minor adaptation of Q932 in the HIV module, are used to construct indicators measuring stigma.userforum.dhsprogram.com/index.php?t=msg\&goto $=1$ $831 \&$ S....

[21] Greeff M, Uys LR, Wantland D, Makoae L, Chirwa M, Dlamini P, Kohi TW, Mullan J, Naidoo JR, Cuca Y, Holzemer WL. Perceived HIV stigma and life satisfaction among persons living with HIV infection in five African countries: a longitudinal study. International journal of nursing studies. 2010 Apr 30; 47(4):475-86.

[22] Mall S, Middelkoop K, Mark D, Wood R, Bekker LG. Changing patterns in HIV/AIDS stigma and uptake of voluntary counselling and testing services: the results of two consecutive community surveys conducted in the Western Cape, South Africa. AIDS Care 2013; 25(2): 194-201.

[23] Apanga PA. HIV/AIDS-related stigma and discrimination in sub-Saharan Africa: a review. J Nat Sci Res 2014; 4(21): 41-8.

[24] Gilbert L, Walker L. 'My biggest fear was that people would reject me once they knew my status...': stigma as experienced by patients in an HIV/AIDS clinic in Johannesburg, South Africa. Health \& social care in the community. 2010 Mar 1;18(2):139-46.

[25] Shisana O, Simbayi LC, editors. Nelson Mandela/HSRC study of HIV/AIDS: South African national HIV prevalence, behavioural risks and mass media: household survey 2002 . HSRC Press; 2002.

[26] Sahn DE, Stifel DC. Urban-rural inequality in living standards in Africa. Journal of African Economies. 2003 Dec $1 ; 12(4): 564-97$.

[27] Morrell R, Jewkes R, Lindegger G. Hegemonic masculinity/masculinities in South Africa: Culture, power, and gender politics. Men and Masculinities. 2012 Apr; 15(1):1130 .

[28] Jacobs JA. Gender inequality and higher education. Annual review of sociology. 1996 Aug;22(1):153-85.

[29] Kabeer N. Gender equality and women's empowerment: A critical analysis of the third millennium development goal 1 . Gender \& Development. 2005 Mar 1; 13(1):13-24.

[30] Mayoux L. Questioning virtuous spirals: micro-finance and women's empowerment in Africa. Journal of international development. 1999 Nov 1; 11(7):957.

[31] Katulushi C. Teaching Traditional African Religions and Gender Issues in Religious Education in Zambia. British Journal of Religious Education. 1999 Mar 1; 21(2):101-11.

[32] Afisi OT. Power and womanhood in Africa: An introductory evaluation. The Journal of Pan-African Studies. 2010 Mar 1;3(6):229-38. 